Case report

\title{
Idiopathic gangrene of the tongue: a case report
}

\section{Anand Pandey*, Lokesh Saluja, Ajay Agarwal and Sudesh K Sagar}

Address: Department of Surgery, Sri Ram Murti Smarak Institute of Medical Sciences, Bareilly, Uttar Pradesh, India

Email: AP* - dranand27@rediffmail.com; LS - lokesh.saluja@rediff.com; AA - drajju74@yahoo.co.in; SKS - drsksagar@ymail.com

* Corresponding author

Received: 2 March 2009 Accepted: II May 2009 Published: 22 June 2009

Cases Journal 2009, 2:6290 doi: 10.4076/1757-1626-2-6290

This article is available from: http://casesjournal.com/casesjournal/article/view/6290

(C) 2009 Pandey et al; licensee Cases Network Ltd.

This is an Open Access article distributed under the terms of the Creative Commons Attribution License (http://creativecommons.org/licenses/by/3.0), which permits unrestricted use, distribution, and reproduction in any medium, provided the original work is properly cited.

\begin{abstract}
Introduction: Gangrene of the tongue is an extremely rare condition. We encountered a 35-yearold patient who presented with this entity.

Case presentation: A 35-year-old male patient from rural background presented with blackening of the tongue. Its exact cause could not be ascertained. Examination revealed it to be gangrene. It was treated with excision of the gangrenous part.

Conclusion: As this is a very rare condition, it is being reported with a brief review of the relevant literature. The treatment must be based on the etiology; however, if the etiology is not known, it must be symptomatic.
\end{abstract}

\section{Introduction}

The tongue is an important part of oral cavity, which helps in taste, salivation, and deglutition. Gangrene of the tongue is an extremely rare phenomenon because of its excellent blood supply. The chief blood supply to the tongue is by the lingual artery. Besides this, the ascending pharyngeal artery and the external facial artery also contribute deep branches to the tongue [1]

We encountered an extremely rare case of gangrene of the oral tongue, the exact etiology of which could not be ascertained. Being a rare entity, it is being reported with a brief review of the relevant literature.

\section{Case presentation}

A 35-year-old male of Indian origin was admitted in the casualty with complaint of blackening of the oral tongue for last three days. The patient was mentally retarded and hence, the exact history could not be ascertained. The attendants noticed a foul smell from the mouth of the patient, and on seeing the black tongue they were horrified. For this reason, they brought the patient to the hospital. There was doubtful history of repeated tongue bite by the patient himself, but there was no history of oral bleeding. There was no history of any other significant associated illness.

On examination, the pulse rate was $78 /$ minute and respiratory rate was $15 /$ minute. The general condition of the patient was satisfactory. On examining the oral cavity, anterior two-third of the tongue was gangrenous (Figure 1). There was foul smell emanating from the mouth.

The patient was shifted to the operation theatre, where resection of the gangrenous tongue was done. The remaining tongue was repaired (Figure 2). The 


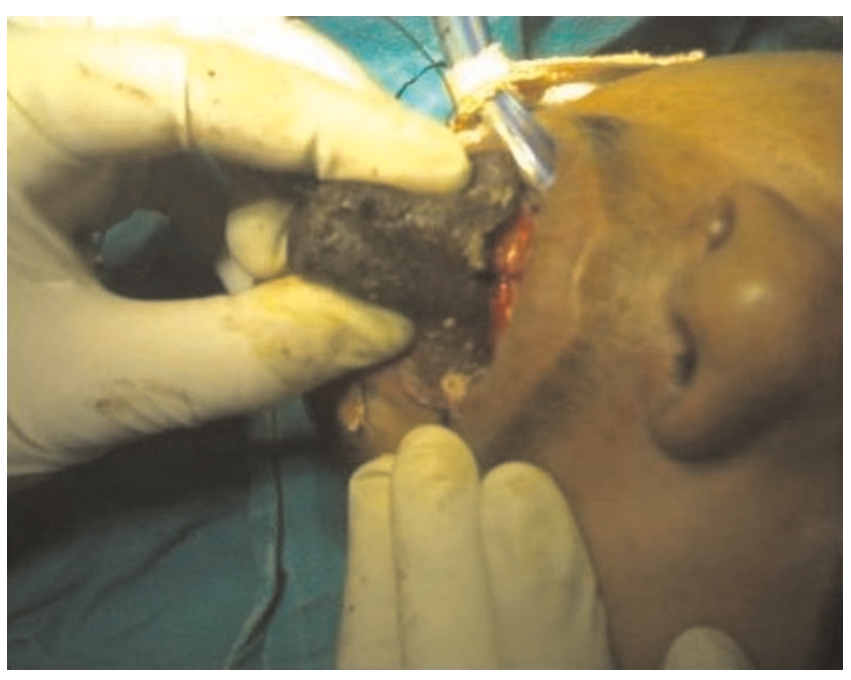

Figure I. Gangrenous tongue, seen at the time of surgery. It was foul smelling.

postoperative period was uneventful. The patient was discharged in a satisfactory condition on seventh postoperative day.

Histopathology of the specimen was non-specific. It reported necrosis in the specimen with specific etiology for it.

\section{Discussion}

The circulatory disturbances of the tongue are extremely rare because of its rich blood supply [2]. Lingual artery, ascending pharyngeal artery and external facial artery form

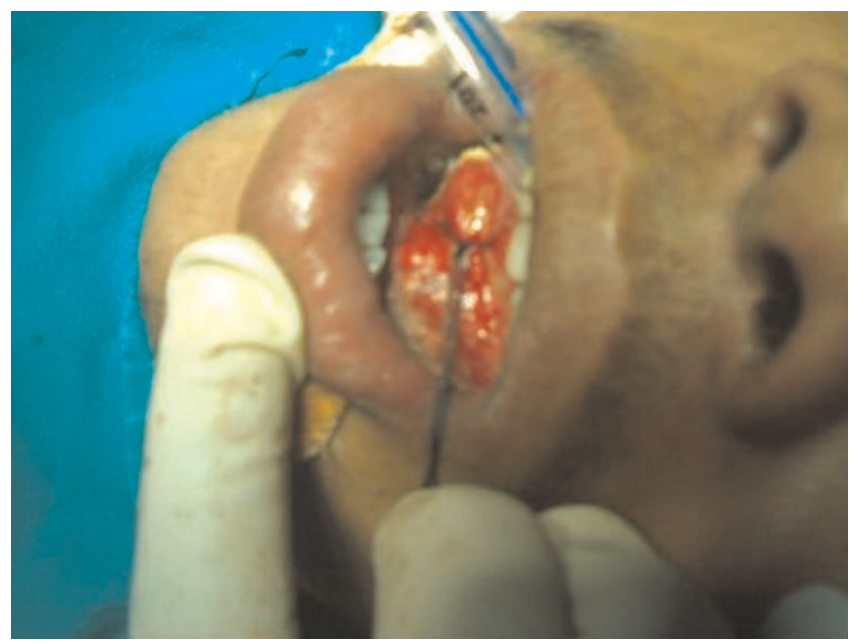

Figure 2. Postoperative view, after excision of the gangrenous part. A thread is tied to prevent tongue fall in the postoperative period. a good network that supplies the tongue; hence, gangrene of the tongue is unlikely [1].

Gangrene of the tongue is a rare phenomenon, less than 30 cases have been reported in the literature. An important cause of gangrene of the tongue is giant cell or temporal arteritis [3-5]. This form of gangrene can be confirmed by the histopathology report. As histopathology of the specimen was non-specific in our patient, this was ruled out to be the cause.

Other reported causes of the gangrene are intra-aortic balloon pump for cardiogenic shock [6], self-application of an elastic rubber band [7], atherosclerotic arterial occlusion [1]. These have been reported merely as sporadic case reports. None of these could be a possibility in our patient.

As the patient was mentally retarded, we were unable to glean the exact history. Based on the history of selfinflicted trauma to the tongue, we speculate that it may be the cause for the gangrene to occur. There may be impairment to the venous drainage, which appears to develop only as a consequence of an extensive posttraumatic or inflammatory edema of the floor of the mouth and tongue base [2]. This impairment of venous drainage may result in a large acute swelling of the tongue, or to ischemia carrying a painful tongue swelling, and possibly tongue necrosis [2]. However, we do agree that exact etiology was not known.

To conclude, gangrene of the tongue is a rare phenomenon. The treatment must be based on the etiology; however, if the etiology is not known, it must be symptomatic.

\section{Consent}

Written informed consent was obtained from the patient for publication of this case report and accompanying images. A copy of the written consent is available for review by the Editor-in-Chief of this journal.

\section{Competing interests}

The authors declare that they have no competing interests.

\section{Authors' contributions}

AA and LS operated upon the patient. AP did the literature review and was the major contributor of the manuscript. SKS helped in literature search. All authors read and approved the final manuscript.

\section{References}

I. Reed C, Inlis MJ: Acute massive gangrene of tongue. $\mathrm{Br} \mathrm{Med} \mathrm{J}$ 1965, 2:575-576

2. Schultz-Coulon HJ, Laubert A: Acute circulatory disorders of the tongue. HNO 1988, 36:77-83. 
3. Currey I: Scalp necrosis in giant cell arteritis and review of the literature. $\mathrm{Br}$ J Rheumatol 1997, 36:8I4-816.

4. Honberg PZ: Giant cell arteritis and gangrene of the tongue. Ugeskr Laeger 1989, I5 I:637-638.

5. Maxit MJ, Moreno C, Brusco JE: Gangrene of the tongue. A form of presentation of temporal arteritis. Medicina (B Aires) 1988, 48:186-I88

6. Morris LG, Komisar A, Liberatore LA: Total gangrene of the oral tongue following intra-aortic balloon pump for cardiogenic shock. Otolaryngol Head Neck Surg 2007, 137:358-359.

7. Dutta T, Vasudevan K: Gangrene of the tongue following selfapplication of a rubber band. Br J Surg 1975, 62:956.

\section{Do you have a case to share?}

Submit your case report today

- Rapid peer review

- Fast publication

- PubMed indexing

- Inclusion in Cases Database

Any patient, any case, can teach us something

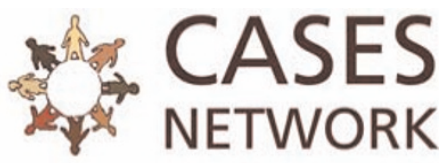

www.casesnetwork.com 